\title{
Effects of Self-Control on Social Adjustment of Azad University Student's Happiness in Khash City
}

\section{Hossein Jenaabadi1 ${ }^{*}$, Bahman Ruzrokh²}

${ }^{1}$ Department of Psychology, Faculty of Psychology and Educational Sciences, University of Sistan and Baluchestan, Zahedan, ${ }^{2}$ Department of Psychology, Faculty of Psychology and Educational Sciences, Islamic Azad University of Zahedan, Zahedan, Iran

*Corresponding Author E-mail: hjenaabadi@ped.usb.ac.ir

Received: 30 November 2019, Revised: 8 January 2020, Accepted: 14 February 2020

\begin{abstract}
This study examines the effects of self-control on social adjustment of Azad university students' happiness Khash city. Research method was a descriptive -survey. The study population consisted all 213 Azad university students in the city of Khash. that Random cluster sampling was in multi-stage and research instrument is self-control questionnaire, social adjustment (personality measurement of California) and the Oxford Happiness. The findings of research suggest that self-control was effectively related to happiness and social adjustment. Also, there was a significant relationship between happiness and social adjustment of students. Further, the results showed that there is no significant difference between students' self-control in terms of genders, but there was a significant difference between social adjustment and happiness of male and female students; male students showed higher happiness and social adjustment than female students.
\end{abstract}

Keywords: Self-Control, Social Adjustment, Happiness, Students of Azad university of Khash.

\section{Introduction}

Among human factors, it seems that selfcontrol play a major role in social compatibility and happiness. Self-control is a unique feature of personality, which is different in various people, that is people who have high self-control show different reactions and different behaviors (Etebarian and Pour Vali, 2008). In other words, self-control is interpersonal conflict between logic and passion, between the cognition and motivation (Rechlin, 2004). The concept of self-control developed by
Schneider in 1974 means how much a person is flexible or stable in self position (Kaushal and kwantes, 2006). Schneider says people generalLY will be divided into two categories: Those with high selfcontrol (self-regulatory) and those with low self-control (self regularity), each of them has features (Kjeldal, 2003). Selfregularity and self-control are very important in many areas of life for the success; self-control is the core of many problems of children and adults. Students 
with high self-control have mental compatibility and better interpersonal relationships (McCullough and Willoughby, 2009). They have less tendency to consume alcohol and drugs (Duck, worth and Seligman, 2006 quoted by McCullough and Willoughby, 2009) people with less control are in the exposure to some of the dangerous behaviors of drug abuse, driving with alcohol consumption, and social incompatibility (Allah Verdi pour et al., 2005). This study aims to examine the effects of self-control on social adjustment of Azad university students' happiness Khash city. It is attempted to test that if there is any relation between self-control and happiness or social adjustment and other parameters.

\section{Literature Review}

self-control include personality logical components. This process will help people to satisfy some of their essential needs, without facing a warning from outside or disputes from their moral criteria. You can consider a child wanting an expensive doll and having to gather money for it. selfcontrol prevents her from stealing doll and while hinder to buy the pin loves, as a result, she keeps its money to purchase doll. A simpler example is a student that due to low concession check waits for months to collect more concession check to be able to receive a better prize from the awards cabinet. The important function of self-processes is balance - over control and too little control is a sign of failing health and a reasonable level control is symptoms of health. Apparently, children, who have flexibility, can have their own control whenever necessary. What procedures do they have for resistance in front of temptation or tolerance to obtain something? The answer to these kinds of questions can be obtained from the experimental findings. Using the experimental task, we can measure resistance against the immediate temptation to satisfy his need. Thus, the child could choose the not-so- tempting sweet (i.e. Ordinary biscuit) or to get the better sweet (sweet coconut) should wait 15 minutes. It is not surprising that when prizes are placed in front of children, they could wait less than when they could see prizes. Of course, the strategies they used to cope with situation were more important than observing the prizes. For example, some children are taught to think about good tastes of foods that were in front of them. Another group was told to imagine that those foods were non - edible objects. They thought that coconuts sweet were as the clouds on air or biscuit resembled a brick of house. Children who imagine food as non-edible objects could wait to eat it compared with those who thought of the taste (Mitchell and Paterson 1978).

The concept of self-control developed by Schneider (1974) means how flexible or how stable a person is in self-position (Kaushal and kwantes, 2006). Schneider says people are divided into two groups generally: People with high self-control (self-regularity) and those with low selfcontrol (self-regularity), each with their own features (Kjeldal, 2003).

Some people are sensitive to the social position and set their appearance with the current situation; we call these people high self-control, whereas people with low selfcontrol have the tendency to express their thinking and feeling to fit it with the situation (Schneider, 1974).

The human capacity to apply self-control, as a controversial issue, is one of the most powerful abilities which can cause useful compatibility in the human psyche. Compatibility is a condition or a situation in which a person's behavior is conformed 
with the needs of a community or culture, to which it belongs, and the person feels the individual needs have been satisfied or will be satisfied (Kazemi, 2009). Compatibility also is defined as the ability to adapt, compromise, cooperation and cope with self, the environment and others. A consistent person is one that has the mental health, but intensive and fast changes usually challenge person's compatibility more seriously, and therefore there is the probability of opposition, conflict, stress and confusion to arise. Lazarus introduced compatibility as an important factor in reducing conflicts between common areas of inside and outside human behavior. Compatibility can be considered as a feature of personality or equivalent and product of a combination of personality characteristics and social, family factors and the like. There is little research on relationship between levels of compatibility and one or more personality characteristics of people (Lazarus, 1993). Lanyon and Goodstein (1997) expressed when physical and psychological balance of person is impaired giving him an unpleasant mode, using the inner forces and external care is required to create ability. In this case, if the person becomes successful in employing new mechanisms and solves the issue by self-advantage, it is said the process of adaptation has occurred. The dimensions of compatibility includes physical adaptation, psychological adjustment, moral consistency, and above all social adjustment. The prerequisite to the psychological, moral and physical compatibility is being socially compatible. When people can create a perfect harmony and compatibility between self and their environment, they will have the happiest and most healthy condition. Compatibility can basically be improved by changing the self to comply with the world around.
In addition, self-ability to avoid antisocial impulses and harmony with needs of group life is a sign of a civilized life. During the last decade, psychologists' attention to the definition of happiness and prediction factors of it and its relationship with personality has increased. Psychologists and researchers, have defined the various forms of happiness concept; for example, Some researchers also know happiness as a positive emotion that has deep effects on physical, mental, cognitive operations in the mechanism and improves human practice in various fields. Also, the Diener and Diener (2008) believe that happiness includes happy mode or joy (positive emotions), being satisfied with the life and the absence of depression and anxiety (negative factors). Happiness is a common goal of humans and all try to have it. It is people's evaluating themselves and their life. This evaluation may be from a cognitive perspective, such as a judgment that made in response to the events of life. Therefore, happiness consists of several components: gratification of life, mood and positive emotions and lack of negative emotions and moods.

In recent years, based on the conducted studies, happiness has been introduced as one of the most effective factors in maintaining the mental health of people. Happiness follows optimal functioning and mental health and that consent of personal relations is connected with optimal mental health. Altruist people in comparison with others are happier and induction of such positive sentiments make people smarter, more productive, accurate, and as a result, happier.

In 2005, Seligman and his colleagues examined the relationship between happiness and life satisfaction. They have introduced happiness with three components, which include strong social services and desirable the social 
component), stable and happy mood modes (emotional component) and the positive interpretation of environment information (cognitive component). The lack of mental health and unhappiness hinder the individual progress and advances, as well as the ability to carry out duties and tasks they are responsible for, and this will eventually affect the society adversely.

According to what stated above, this research wants to show whether selfcontrol has effects on social adjustment and happiness of Azad university students of Khash. What follows is a review of research on the same area.

Hassan Zadeh (2007) examined the relationship between happiness and adaptation (emotional, social, educational) among secondary school students in the city of Karaj. The results showed there is a significant relationship between adaptation and happiness and also between affective adaptation with happiness. Also, there is no significant relationship a positive significant relationship, but between social adaptation with happiness and education adaptation with happiness. McCullough and Willoughby (2009) study entitled "religion, self-regularity and self-control: evokes, commentary, meaning" showed that religion has positive relationship with the self-control and with traits such as conscience and compatibility which many theorists know them as the sub shapes of self-controlFurther, they showed that religious parents tend to have children with high self-control but still there is no robust evidence to assess whether the religion is causes of self-control or selfregularity; it is relatively minimal. The research by Muraven (2010) entitled "build a strong self-control: self-control practice leads to improvement in the performance", self-control capacity of 92 adults using the stop signal pattern prior to a workout was assessed. The same assessment was repeated after 2 weeks. It showed that participants who had been practicing self-control had a meaningful recovery than those who had not practicing self-control. This indicated that the action to the self-control in small tasks for 2 weeks led to a significant improvement in the laboratory measurement of the self-control and participants' resistance to eat sweets and against 2 times fights off in the day, showed a meaningful recovery to response of harness. In a nutshell, it showed that the self-control exercises make self-control capacity and increases the power of selfcontrol and stability.

Khankhani Zadeh and Bagheri (2012) studied the effectiveness of verbal selfeducation on social adaptation improvement. The results showed that verbal self-education had a positive impact on social adaptation of students with learning disability. The overall goal of this study was to determine the influence of self-control on the social adaptation and students' happiness of Azad University in Khash city. To achieve the goal of this research, effort was made to test the following major hypothesis:

1. Self-control has effects on social adjustment and happiness of Azad university students in Khash city. The following are the sub hypothesis:

1 - There is a relationship between selfcontrol and social adjustment of Azad university students Khash city.

2 - There is a relationship between selfcontrol and happiness Azad university students Khash city.

3 - There is a relationship between social adjustment with happiness Azad university students Khash city. 
4 - There is difference between selfcontrol of male and female of Azad university students Khash city.

5 - There is a difference between social adjustments of male and female of Azad university students Khash city.

6 - There is a difference between happiness of male and female of Azad university students Khash city.

\section{Method}

The present study was a descriptive survey research. The study sample consisted of Azad university students in Khash city. Sampling followed multistage random sampling technique was used. The sample size of 226 people was determined according to Morgan.

\section{Measures}

To collect data related to research variables, three standardized research questionnaires were used as follows:

1. The self-control questionnaire: The questionnaire consists of 36 items, 5 options Likert. The minimum score is 36 and maximum score is 180 . In the present study, the validity of the questionnaire was confirmed by experts and its reliability using Cronbach's Alpha was 0/79.

2. Adjustment questionnaire: California Personality measurement (CTP) in the field of social adjustment was applied with 90 questions in yes and no question, zero for no and one for yes. Validity and reliability of the questionnaire has been evaluated in several studies. Masudi Nejad (1986) reported reliability coefficient of the test for social adjustment by $0 / 78$. Reliability of the questionnaire using Cronbach's alpha was $0 / 64$. In the present study, the questionnaire validity was confirmed by experts and its reliability using Cronbach's Alpha was 0/85.

3. Oxford happiness questionnaire with 29 questions in Likert. Happiness has three parts: a positive emotion, satisfaction and lack of negative emotion. The highest score obtained in this questionnaire is 87 , which represents the highest level of happiness of the individual and the lowest score is 0 . Normal score of this test is 40 to 42 . The score less than 40 to 42 in terms of the amount of happiness is in low status and 40 to 42 to more score represents happiness as high so whatever score you earn is closer to the highest amount of (87) is an indicator of more happiness. In the present study, the aforementioned questionnaire validity was confirmed by experts and reliability of it using the method of Cronbach's alpha was calculated 0.91 .

\section{Results}

First hypothesis: There is a relationship between self-control and social adjustment of Azad university students in Khash city.

To test this hypothesis, Pearson correlation and linear regression analysis were used as shown in Table 1.

Table 1. Results of descriptive statistics and Pearson correlation coefficients and regression of selfcontrol and social adjustment

\begin{tabular}{ccccccccc}
\hline Variables & number & mean & SD & $\mathbf{R}$ & $\begin{array}{c}\text { Adjusted } \\
\mathbf{R}^{2}\end{array}$ & $\begin{array}{c}\text { standard } \\
\mathbf{B}\end{array}$ & $\mathbf{T}$ & Sig \\
\hline $\begin{array}{c}\text { Self-control } \\
\text { Social }\end{array}$ & 213 & $99 / 38$ & $19 / 54$ & & & & & \\
adjustment & 213 & $48 / 32$ & $9 / 05$ & $0 / 144$ & $0 / 016$ & $0 / 144$ & $2 / 11$ & $0 / 03$ \\
\hline
\end{tabular}


Results of Table 1 shows students' selfcontrol having a mean of 99/38 and SD of $19 / 54$ and the mean social adjustment by $48 / 32$ and SD by $9 / 05$. The above table also shows that the correlation of selfcontrol and social adjustment is equal to $r=0 / 144$ significant at the $95 \%$ confidence level $(\mathrm{p}<0 / 05)$. Therefore, we can conclude statistically that there a relationship between self-control and social adjustment of Azad university students in Khash city. Also, regression analysis results supported the correlation between self-control and the social adjustment with the amount of adjusted $\mathrm{R}^{2}$ $(0 / 016)$. Second hypothesis: There is a relationship between self-control and happiness among Azad university students in Khash city.

To test this hypothesis, Pearson correlation and linear regression analysis were used as are shown in Table 2 .

Table 2. Descriptive statistics and Pearson correlation coefficients and regression results of selfcontrol and happiness

\begin{tabular}{ccccccccc}
\hline Variables & number & mean & SD & $\mathbf{R}$ & $\begin{array}{c}\text { Adjusted } \\
\mathbf{R}^{2}\end{array}$ & $\begin{array}{c}\text { standard } \\
\mathbf{B}\end{array}$ & t & Sig \\
\hline $\begin{array}{c}\text { Self-control } \\
\begin{array}{c}\text { Social } \\
\text { adjustment }\end{array}\end{array}$ & 213 & $99 / 38$ & $19 / 54$ & $0 / 25$ & $0 / 058$ & $0 / 25$ & $3 / 73$ & $0 / 000$ \\
\hline
\end{tabular}

Table 2 shows students' self-control had mean of $(99 / 38$ and SD by $19 / 54$, and the happiness with the mean of $69 / 47$ and SD by $10 / 49$. Table 2 also shows that the correlation of self-control and happiness is equal to $r=0 / 250$ with the $99 \%$ confidence level which is significant $(\mathrm{p}<0 / 01)$. Therefore, we can conclude statistically that there is a relationship between selfcontrol and the happiness of Azad university students in Khash city. Also, regression analysis results indicated that self-control can have impact on the happiness of the adjusted $R^{2}(0 / 058)$, and predict it.

Third hypothesis: There is a relationship between Social Adjustments with happiness Azad university students Khash city.

To analyze this hypothesis, Pearson correlation coefficient tests and regression were as shown in Table 3.
The results in Table 3 show that the social adjustment of students have a mean of $48 / 32$ and SD by $9 / 05$ and the mean happiness of $69 / 47$ and SD by $10 / 49$. Table 3 also shows that the correlation coefficient of happiness and social adjustment equals to $r=0 / 234$ with $99 \%$ significant at a confidence level $(\mathrm{p}<0 / 01)$. So, statistically, we can conclude that there is a relationship between social adjustment and happiness of Azad university students Khash city. Also, regression analysis results also suggest that social adjustment, with the adjusted $\mathrm{R}^{2}$ (0/050), can have impact on happiness and predict it.

Fourth hypothesis: There is a difference between self-control of male and female of Azad university students Khash city.

Table 4 shows the results of the independent $t$-test with respect to selfcontrol differences with regard to gender.

Table 3. Results of descriptive statistics and Pearson's correlation and regression in social adjustment and happiness 


\begin{tabular}{ccccccccc}
\hline \hline Variables & number & mean & SD & R & $\begin{array}{c}\text { Adjusted } \\
\mathbf{R}^{\mathbf{2}}\end{array}$ & $\begin{array}{c}\text { standard } \\
\mathbf{B}\end{array}$ & t & sig \\
\hline $\begin{array}{c}\text { Self- } \\
\text { control }\end{array}$ & 213 & $48 / 32$ & $9 / 05$ & $0 / 23$ & $0 / 050$ & $0 / 234$ & $3 / 48$ & $0 / 001$ \\
$\begin{array}{c}\text { Social } \\
\text { adjustment }\end{array}$ & 213 & $69 / 47$ & $10 / 49$ & & & & & \\
\hline
\end{tabular}

Table 4. Results of the independent $t$ test for the self-control difference between male and female students

\begin{tabular}{cccccccc}
\hline Variables & Gender & number & mean & SD & t & df & sig \\
\hline Self- & Female & 95 & $98 / 67$ & $17 / 63$ & $-0 / 47$ & 211 & $0 / 63$ \\
control & Male & 118 & $99 / 95$ & $21 / 01$ & & & \\
\hline
\end{tabular}

The results of Table 4 suggest that selfcontrol of females have mean of $98 / 67$ and SD by $17 / 63$ and male students with a mean of $99 / 95$ and SD by $21 / 01$. Also, the results show that $t$ calculated by $-0 / 476$ with 211 degrees of freedom is not significant at $95 \%(\mathrm{p}>0 / 05)$. Thus, it can be concluded that there is no difference between the self-control of male and female university students in Khash city Fifth hypothesis: There is a difference between social adjustments of male and female of Azad university students Khash city.

Table 5 shows the results of the independent $t$ test related to happiness differences according to gender.

Results in Table 5 show that females in social adjustment have mean of $45 / 81$ and SD of 7/88 and males with mean of 50/35 and SD of $9 / 45$. Also, the results show that $t$ calculated of $-3 / 75$ with degrees of freedom 211 is significant at the $99 \%$ level $(\mathrm{p}<0 / 01)$. So, we can conclude that there is a difference between the social adjustment of male and female of Azad university students in Khash city, so male students have higher social adjustment.

The sixth hypothesis: There is a difference between happiness of male and female of Azad university students in Khash city.

Table 6 shows the results of the independent $t$ test related to happiness differences according to gender.

Results in Table 6 indicate that females in happiness have a mean of $67 / 23$ and SD by $8 / 66$, and male students have a mean of $71 / 29$ and SD by $11 / 48$. Also, the results show that $t$ calculated by $-2 / 85$ and degrees of freedom by 211 is significant at the $99 \%$ level $(p<0 / 01)$. So, we can conclude that there is a difference between happiness in male and female students of Azad University in Khash city, with higher rate of happiness belonging to males.

Table 5. Results of the independent $t$ test related to the happiness difference between male and female students' social adjustment

\begin{tabular}{llllllll}
\hline Variables & gender & number & mean & SD & t & df & sig \\
\hline Social & Female & 95 & $45 / 81$ & $7 / 88$ & $-3 / 75$ & 211 & \multirow{2}{*}{$0 / 000$} \\
adjustment & Male & 118 & $50 / 35$ & $9 / 45$ & & & \\
\hline
\end{tabular}

Table 6. Results of the independent $t$ test related to happiness difference of males and females students 


\begin{tabular}{llllllll}
\hline \hline Variables & gender & number & mean & SD & t & df & sig \\
\hline \multirow{2}{*}{ Happiness } & Female & 95 & $67 / 23$ & $8 / 66$ & \multirow{2}{*}{$-2 / 85$} & \multirow{2}{*}{211} & \multirow{2}{*}{$0 / 005$} \\
& Male & 118 & $71 / 29$ & $11 / 48$ & & \\
\hline
\end{tabular}

\section{Conclusion}

Today, it seems most of the major individual and social problems arise from a defect in the self-control. The findings of investigators and researches suggest that people generally have different selfcontrol capacity. Some people can manage their life better than others, control their anger, have a moderate nutrition, do the duties, have savings, job stability, and are confident. The public mental health experts put emphasis on the role and the importance of happiness in life and know it as the most important causes of mental health promotion in the community; however, it seems that happiness is the missing link of mental health in our society, a society in which various methods and excuses are recognized to cry, but methods of expressing happiness are ambiguous and very limited. Also, among the human factors, it seems self-control plays a major role in social integration and happiness. Self-control is a unique personality characteristic that is different in various people, meaning people who have high Self-control, they show different reactions and different behaviors, in other words, Self-control is interpersonal conflict between reason and

passion, between the knowledge and motivation. Generally, the findings suggest that there are relationships between selfcontrol with happiness and social adjustment.. Also, a significant relationship was observed between happiness and social adjustment of students. Independent $t$-test results showed that there was no significant difference between student self-control in terms of gender but, there was a significant difference between social adjustment and happiness between male and female students with male students having higher levels of happiness and social adjustment than females.

\section{Acknowledgment}

Here we need to be thankful from Islamic Azad university principals in Zahedan to help us conduct this paper.

\section{References}

Allah Verdi Poor, H, Heiydarnia, A, Kazemnezhad,A. (2005). Investigating the status of drug abuse in students and integrating self-control factor in EPPM model, Journal of Shaheed Sadoughi University of Medical Sciences \& Health Services, 13(1):21-31.

Diener, E, Biswas-Diener, R. (2008). Happiness: unlocking the mysteries of psychological wealth, New Jersey: Blackwell Publishing.

Etebarian, A, Poor Vali, Z. (2008). Determine the relationship between selfcontrol and conflict resolution strategies among Azad Khorasgan university staff (Esfahan), New approach in Educational Administration Quarterly, 1(2): 111-130.

Khankhani Zadeh, H, Bagheri, S. (2012). The effectiveness of verbal self-learning on improving social cohesion of students with learning disabilities, Journal of Learning Disabilities, 2(1):43-52.

Kaushal, R, Kwantes, C.T. (2006). The role of culture and personality in choice of conflict management strategy, International Journal of Intercultural Research, 30: 579-603. 
Kjeldal, S.E. (2003). Self-Monitoring and Consumer Behavior, The Qualitative Report, 8( 3): 353- 376.

Hassan Zadeh, KH.S. (2012). Relationship between happiness and adjustment (emotional, social, educational) among high school students in the city of Karaj, MA thesis in General psychology, Islamic Azad University of Karaj, Alborz.

Lazarus, R.S. (1993). Coping theory and research: past, present and future, Psychosomatic Medine, 55: 234-247.

Lanyon, R, Goodstein, L.D. (1997). Personality Assessment New York: John Wiley \& Sons, Inc.
McCullough, M, Willoughby, B. (2009). Religion, self-regulation and self-control: associations, explanations, and implications, Psychological Bulletin, 135(1): 69-93.

Muraven, M. (2010). Building self- Control strength: practicing self-control leads to improved self-control performance, Journal of Experimental Social Psychology, 46: 465-468.

Schneider, M. (1974). Turtle technique in the classroom, Teaching Exceptional Children, 7: 21-24.

How to cite this article: Hossein Jenaabadi, Bahman Ruzrokh, Effects of Self-Control on Social Adjustment of Azad University Student's Happiness in Khash City. International Journal of Advanced Studies in Humanities and Social Science, 2020, 9(1), 63-71. http://www.ijashss.com/article 105617.html 